\title{
A ADESÃO DE NOVOS MEMBROS COOPERADOS: ESTUDO DE CASO EM UMA COOPERATIVA DE TRABALHADORES EM MATERIAL RECICLÁVEL
}

Edilene Mayumi Murashita Takenaka, Yeda Ruiz Maria, Ademir Alves, Alexandre Maximiliano Silvestrini da Silva, Claudio Girotto, Gabriel Barbosa Nogueira, Hugo Gonçalves Pereira

Mestrado em Meio Ambiente e Desenvolvimento Regional - UNOESTE. Curso Superior de Tecnologia em Gestão Comercial - UNOESTE. E-mail: edilene@unoeste.br

\section{RESUMO}

Cooperativa é uma palavra utilizada para designar uma sociedade de pessoas que se unem voluntariamente para exercer a mesma atividade, baseando-se nos valores de responsabilidade, democracia, igualdade e solidariedade. A presente pesquisa teve como objeto de estudo uma cooperativa de trabalhadores voltada à coleta e comercialização de materiais recicláveis no município de Presidente Prudente-SP. Com o objetivo de analisar o processo de inclusão e o grau de conscientização de novos cooperados foi realizada uma pesquisa descritiva seguindo com estudo de caso, apoiado em pesquisa bibliográfica para construção do referencial teórico, com a aplicação de questionários para a coleta dos dados necessários. Identificamos que o desligamento dos cooperados estão relacionados à busca por estabilidade como a carteira de trabalho assinada, a renda mensal baixa e oscilante e o processo de adesão e manutenção dos cooperados na organização depende de um aprimoramento na forma de conscientização e preparo de seus novos membros.

Palavras-chave: Cooperativa. Cooperativismo. Adesão. Material reciclável. Sociedade.

\section{INTRODUÇÃO E OBJETIVO}

O município de Presidente Prudente, localizado no extremo oeste do Estado de São Paulo, possui aproximadamente 207 mil habitantes e conta com um serviço de coleta de resíduos sólidos, e disposição final feita em local considerado aterro controlado pela prefeitura municipal. Este serviço é prestado por uma empresa de economia mista (PRUDENCO) contratada pela Prefeitura Municipal.

Presidente Prudente, em comum com a maioria dos municípios brasileiros, apresenta a coleta seletiva de materiais recicláveis a partir de articulações da sociedade organizada, uma vez que o poder público municipal encontra dificuldades em sua implantação.

Assim, a partir de 2003, ocorreram diversas parcerias entre: universidades, entidades, sociedade civil e poder público municipal em prol da constituição de uma cooperativa de catadores de materiais recicláveis com o intuito de iniciar a coleta seletiva no município e contribuir para a educação ambiental. Com isso, surgiram as bases para a origem da cooperativa de trabalhadores em materiais recicláveis, objeto da pesquisa: a COOPERLIX. 
No dia 14 de Abril de 2010, o lixão da cidade de Presidente Prudente foi fechado definitivamente em cumprimento ao Termo de Ajustamento de Conduta (TAC), todos os catadores tiveram que deixar o lugar, e para minimizar o impacto causado nestas famílias, várias reuniões foram efetuadas com o objetivo de amparar os catadores que permaneciam no local. A Prefeitura propôs a contratação temporária deste pessoal e futuro encaminhamento à todos os que aceitassem as regras do estatuto da COOPERLIX, à integração ao quadro da cooperativa.

Cooperativa é uma sociedade de pessoas que se unem voluntariamente para exercer a mesma atividade, baseando-se nos valores de responsabilidade, democracia, igualdade e solidariedade. Seu objetivo não é apenas para satisfazer a necessidade de consumo dos cooperados, mas também a necessidade social e educativa. As cooperativas consideram, em sua formação, valores de ajuda mútua, responsabilidade, democracia, igualdade, equidade e solidariedade.

Após a sua formação a cooperativa se potencializa através dos cooperados e dos recursos de cada um, forma-se um capital que por fim é dividido entre os mesmos mostrando ao cooperado a sua importância e a responsabilidade que deve ter com a cooperativa. $A$ inclusão de novos membros cooperados tem por finalidade o fortalecimento da cooperativa.

Segundo OLIVEIRA (2011), o cooperativismo é formado por uma doutrina econômica estruturada para a geração de riquezas através do livre associativismo entre pessoas que espontaneamente concordam em criar uma cooperativa em qualquer segmento produtivo permitido pela legislação.

A palavra cooperativismo não é apropriada para designar o conjunto e cooperativas, o termo adequado é sistema cooperativista ou movimento cooperativista destinado ao conjunto de cooperativas e as instituições a elas ligadas. A palavra cooperativa se refere ao empreendimento que atua no mercado em nome dos associados. (IRION ,1997)

Segundo Arana (2006, p.23):

A doutrina do cooperativismo pode ser vista desde os tempos mais antigos quando os homens usavam a cooperação como alternativa para sobrevivência através da pesca, caça e habitação, entre eles existia um ideal em comum que a sobrevivência.

Com isto entendemos que o cooperativismo busca tanto satisfazer suas necessidades financeiras e realização pessoal/profissional através da produtividade e da valorização humana e não da exploração do homem pelo homem. 
Para a formação de uma cooperativa, os membros se unem por adesão. Tal adesão nas sociedades cooperativas ocorre nos termos da lei sendo livre e a todos que desejarem utilizar serviços prestados pela sociedade, desde que aceitem aderir aos propósitos sociais e preencham as condições estabelecidas nos estatutos, ressalvados os casos em que o excesso de associados inviabiliza as operações da cooperativa.

Admissão de novos membros pode restringir-se à pessoa do cooperado, em razão da sua atividade ou profissão ou de sua vinculação com determinada entidade.

Quanto a sua saída esta se dá por Demissão, e, nesse caso, o pedido compete única e exclusivamente ao associado ou também por motivo de exclusão ou eliminação, em virtude de infração legal ou estatutária, ou decorrência de fatos específicos previstos nos estatutos, conforme dispõe o artigo 21, INCISO III da lei n.o 5.764/71. (POLONIO, 2006)

A partir de sua formação, a cooperativa obedece a um regimento elaborado em assembleia onde os cooperados possuem direito a voto.

Segundo Arana (2006) e Polônio (2006), nas sociedades cooperativas, as quotas representativas de seu capital são de um único tipo, não conferindo portanto, direitos políticos diferenciados em relação ao associado, portanto independente de sua atividade dentro da cooperativa, o voto tem peso único na formação da nova diretoria.

Portanto, conhecer o processo que abrange a inclusão de novos cooperados, os motivos que levam à desistência de antigos membros e o grau de conscientização de novos cooperados, especificamente em uma cooperativa de trabalhadores em material reciclável do município apresenta-se como fator fundamental para a construção do conhecimento sobre o tema e o oferecimento de alternativas para seu desenvolvimento.

O objetivo da presente pesquisa foi analisar o processo de inclusão e o grau de conscientização de novos cooperados em uma cooperativa de trabalhadores em material reciclável do município de Presidente Prudente-SP.

\section{METODOLOGIA}

O presente projeto concentra-se no campo das ciências sociais aplicadas em que, segundo Cervo, Bervian e Silva (2007, p. 60), “[...] o investigador é movido pela necessidade de contribuir para fins práticos mais ou menos imediatos, buscando soluções para problemas concretos". Daí, a pesquisa aplicada concentrar-se na produção de conhecimentos que venham a gerar utilidades práticas e específicas. 
Utilizamos a pesquisa bibliográfica com base em informações que coletadas por meio de livros e documentos com o intuito de construir um referencial teórico do assunto tratado e delimitamos o nosso universo de pesquisa a um estudo de caso realizado em uma cooperativa de trabalhadores em produtos recicláveis.

Conforme dispõe Goldenberg (1997, p. 33), “O estudo de caso não é uma técnica específica, mas uma análise holística, a mais completa possível, que considera a unidade social estudada como um todo, [...] com o objetivo de compreendê-los em seus próprios termos".

Ressaltamos, ainda, que este trabalho científico, se caracteriza como uma pesquisa Descritiva, conceito que pode melhor ser elucidado pelos ensinamentos de Cervo, Bervian e Silva (2007, p. 61),

A pesquisa descritiva observa, analisa e correlaciona fatos ou fenômenos (variáveis) sem manipulá-los. Procura descobrir, com a maior precisão possível, a frequência com que um fenômeno ocorre, sua relação e conexão com outros, sua natureza e suas características.

Cabe destacar que foram realizadas entrevistas e aplicação de questionários para um grupo de 10 trabalhadores cooperados (a pesquisa foi realizada em um momento que a cooperativa contava com um número aproximado de 40 associados) cujo procedimento foi aprovado pela Coordenadoria Central de Pesquisa (CCPq) e seus comitês de apoio ao desenvolvimento da pesquisa: CAPI (Comitê Assessor de Pesquisa Institucional) e CEP (Comitê de Ética em Pesquisa). (Protocolo 1399/2012)

\section{RESULTADOS}

Os dados coletados a partir dos questionários aplicados são apresentados na tabela a seguir: 
Tabela 1. Dados obtidos a partir de questionários aplicados junto aos trabalhadores cooperados.

\begin{tabular}{|c|c|}
\hline Tempo de trabalho na cooperativa & $\begin{array}{l}\text { - 70\%: entre } 1 \text { e } 5 \text { anos; } \\
\text { - 10\%: entre } 6 \text { e } 10 \text { anos; } \\
\text { - 20\%: entre } 11 \text { e } 15 \text { anos. }\end{array}$ \\
\hline Renda familiar & $\begin{array}{l}\text { - 60\%: de } 1 \text { a } 3 \text { salários mínimos; } \\
\text { - 40\%: acima de } 4 \text { salários mínimos. }\end{array}$ \\
\hline Experiência profissional anterior & $\begin{array}{l}\text { - 40\%: catadores no lixão do município; } \\
\text { - 30\%: empregadas domésticas; } \\
\text { - 20\%: desempregados; } \\
\text { - 10\%: catadores para outras empresas. }\end{array}$ \\
\hline Faixa etária & $\begin{array}{l}\text { - 20\% entre } 18 \text { e } 30 \text { anos; } \\
\text { - 20\%: entre } 31 \text { e } 40 \text { anos; } \\
\text { - 20\%: entre } 40 \text { e } 50 \text { anos; } \\
\text { - 40\%: acima dos } 50 \text { anos. }\end{array}$ \\
\hline Grau de escolaridade & $\begin{array}{l}\text { - 40\%: ensino fundamental completo; } \\
\text { - 30\%: ensino fundamental incompleto; } \\
\text { - 20\%: ensino médio completo; } \\
\text { - 10\%: ensino médio incompleto. }\end{array}$ \\
\hline $\begin{array}{l}\text { Periodicidade das reuniões com a } \\
\text { diretoria da cooperativa }\end{array}$ & $\begin{array}{l}\text { - 50\%: uma vez por mês; } \\
\text { - 30\%: duas vezes por mês; } \\
\text { - 20\%: às vezes. }\end{array}$ \\
\hline Treinamento realizado na cooperativa: & $\begin{array}{l}\text { - 40\%: palestras semanais; } \\
\text { - 20\%: palestras mensais; } \\
\text { - 40\%: não há treinamento. }\end{array}$ \\
\hline $\begin{array}{l}\text { Quanto aos horários e metas estipulados } \\
\text { aos cooperados }\end{array}$ & $\begin{array}{l}\text { - 50\%: acreditam que os cooperados tem } \\
\text { compromisso com horários, mas não com metas; } \\
\text { - 50\%: acreditam que não há compromisso por parte } \\
\text { dos cooperados nem com horários, nem com metas. }\end{array}$ \\
\hline
\end{tabular}

Fonte: Pesquisa de campo (novembro/2012)

Elaborado pelos autores.

Quando questionamos os componentes da diretoria sobre a forma de adesão de novos cooperados ficou claro que, de acordo com o regimento da cooperativa, os mesmos são aceitos pelo conselho de administração desde que seja capaz de desenvolver as atividades na área de ação da cooperativa e que concorde com o que dispõe o estatuto e não exercendo outras atividades que possam colidir ou prejudicar os interesses e objetivos da sociedade.

Os componentes da diretoria da cooperativa afirmaram que os candidatos a cooperados são entrevistados e que aqueles oriundos da catação são observados com maior cuidado, uma vez que tirar os catadores do lixão foi um dos objetivos para a criação da cooperativa. Entretanto, os mesmos comentaram que normalmente, o candidato é indicado por um parente ou amigo membro da cooperativa . 


\section{DISCUSSÃO}

Observamos que a cooperativa possui um quadro de trabalhadores formado por pessoas com 40 anos ou mais (cerca de 60\%). Durante as entrevistas, muitos comentaram estar preocupados com a aposentadoria e grande parte dos entrevistados com menos de 30 anos mencionaram ficar na cooperativa até o surgimento de uma oportunidade de emprego com carteira assinada.

Em relação aos treinamentos, $60 \%$ dos cooperados entrevistados consideraram as palestras proferidas pelos alunos de psicologia para melhorar a auto-estima como uma forma de treinamento, enquanto que os demais (40\%), não identificaram qualquer tipo de treinamento para os trabalhadores.

O contato com a diretoria da cooperativa mostra-se insuficiente para que os cooperados compreendam a cultura cooperativista e, nesse caso, talvez os próprios componentes da diretoria estejam confusos quanto a seu conceito.

Soma-se a esses fatos a insatisfação dos cooperados com os ganhos mensais e a falta de comprometimento de sua maioria quanto ao cumprimento de horários e de metas de produtividade e temos como consequência a alta rotatividade entre os membros cooperados.

\section{CONCLUSÃO}

A criação da Cooperativa de Trabalhadores em Material Reciclável tinha como objetivo dar condições aos "catadores" oriundos do "lixão" municipal, uma vida com melhor qualidade e dignidade.

Entretanto, a maneira encontrada para a adesão de novos cooperados apresenta-se como um problema na medida em que o vínculo de amizade ou de parentesco entre cooperados pode atrapalhar no momento de penalizar o mesmo em caso de deslizes.

Em relação ao grau de conscientização e a permanência de novos cooperados, percebemos que muitos negligenciam as atividades na cooperativa, seja no cumprimento de horários ou de metas devido à ausência de um treinamento adequado reforçado por um maior contato com os membros da diretoria quanto ao conceito de uma cultura cooperativista.

Lembramos que a definição de cooperativa envolve responsabilidade, democracia, igualdade e solidariedade. 
O novo cooperado deve ingressar ciente dos seus direitos e deveres, ter comprometimento com a organização e ser preparado antes de iniciar suas atividades, deve conhecer o estatuto e segui-lo, deve influenciar e não ser influenciado.

Caso haja mudança na maneira de seleção os novos membros e os atuais, seguirem o estatuto e se comprometerem com a cooperativa, automaticamente terão melhores rendimentos mensais diminuindo as evasões.

\section{REFERÊNCIAS}

ARANA, A. A. Cooperativismo uma alternativa de gestão. São Paulo:Macromidia, 2006.

CARDONE, V. Cooperativas de trabalho: legalidade e subsistência - São Paulo: Editora Antiqua 2007.

CERVO, A. L.; BERVIAN, P. A.; SILVA, R. Metodologia científica. 6. ed. São Paulo: Pearson Prentice Hall, 2007.

GOLDENBERG, M. A arte de pesquisar: como fazer pesquisa qualitativa em ciências sociais. Rio de Janeiro: Record, 1997.

IRION, J. Cooperativismo e Economia Social: a prática do cooperativismo como alternativa para uma economia centrada no trabalho e no homem. São Paulo: STS, 1997.

LAKATOS, E. M.; MARCONI, M. de A. Fundamentos de metodologia cientifica - São Paulo: Atlas, 7 Ed.

OLIVEIRA, D.P. e REBOUÇAS, M. Gestão das cooperativas: uma abordagem prática - 5. Ed. - São Paulo: Atlas, 2011.

POLONIO, W. A. Manual das Sociedades Cooperativas. São Paulo:Atlas, 2006.

RAMPAZZO, L. Metodologia científica: para alunos dos cursos de graduação e pós-graduação. 2 . Ed. São Paulo: Loyola, 2004. 